\title{
Modeling of Machining Force in Hard Turning Process
}

\author{
Souâd MAKHFI*, Kamel HADDOUCHE**, Abdelghafour BOURDIM***, Malek \\ HABAK**** \\ *Laboratory of Industrial Technologies, Ibn Khaldun University of Tiaret, B. P. 78 Tiaret 14000, Algeria, \\ E-mail:msouad71@gmail.com \\ **Laboratory of Industrial Technologies, Ibn Khaldun University of Tiaret, B. P. 78 Tiaret 14000, Algeria, \\ E-mail: haddouchekam@gmail.com \\ ***Laboratory of Water and Constructions in their Environment, Abou Bekr Belkeid University of Tlemcen, B. P. 230 \\ Chetouane 13000 Tlemcen, Algeria,E-mail: bourdim56@yahoo.fr \\ ****Laboratory of Innovate Technologies, Picardie Jules Verne University of Amiens, Avenue des Facultés, Le Bailly \\ 80025 Amiens Cedex 1, France, E-mail: malek.habak@u-picardie.fr \\ crossref http://dx.doi.org/10.5755/j01.mech.24.3.19146
}

\section{Introduction}

In machining process, cutting forces are factors that manufacturers must control to ensure better performances. Cutting forces are reliable variables; for this purpose, they were used in various applications such as the adaptive control, the monitoring and the on-line estimation of tool wear. Modeling of machining forces is one of the major problems in the theory of cutting. Many parameters influence greatly the machining forces, so it is quite difficult to develop a theoretical model to describe efficiently the cutting process. The problem of modeling or predicting machining forces has been investigated by many researchers [1-12].

In this study, an ANN approach is proposed to predict machining force components in hard turning of an AISI 52100 bearing steel using CBN cutting tool. Machining parameters such as cutting speed, feed, dept-of-cut and workpiece hardness are taken as inputs of the ANN while machining force components such as feed-force, radialforce and tangential-force are the outputs. To show the effectiveness of the developed ANN, the results of machining force prediction will be confronted with experimental data. Also, the ANN results were compared to those obtained by MLR model.

\section{ANN approach and MLR modeling}

The neural network approach is a technique based on the statistical regression. It can be used in various fields of engineering for modeling complex relationships which are difficult to describe by physical models.

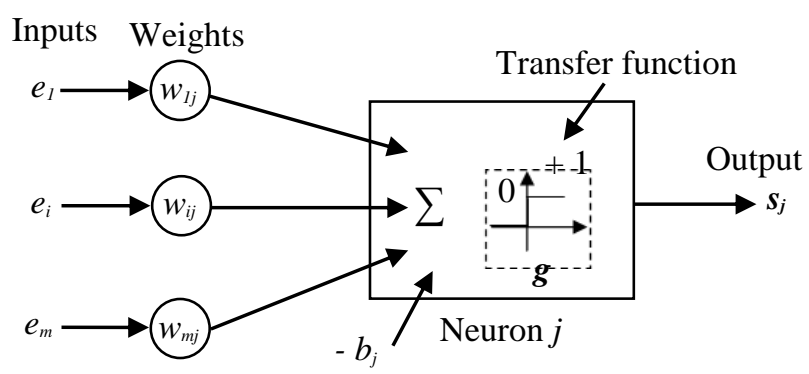

Fig. 1 Mathematical model of an artificial neuron
An ANN consists of simple processors called neurons interconnected. The model of an artificial neuron is illustrated in Fig. 1 (model of McCulloch and Pitts [13]).

The neuron output $s_{j}$ is calculated as:

$$
s_{j}=g\left(\sum_{i=1}^{m} w_{i j} \cdot e_{i}-b_{j}\right) .
$$

When the activation level reaches or exceeds the bias $b_{j}$, then the argument of the transfer or activation function $g$, applied to the sum of the inputs, becomes positive (equal to +1 ); if not, it is zero. The bias is much like a weight, except that it has a constant input of -1 .

Notice that weights $w_{i j}$ of neuron inputs $e_{i}$ and $b_{j}$ are both adjustable scalar parameters of the neuron. Typically the transfer function is chosen by the designer and then the parameters $w_{i j}$ and $b_{j}$ will be adjusted by some learning or training algorithm so that the neuron input-output relationship meets some specific goal.

The ANN architecture has an input vector receiving input data, an output layer which sends final information to users, and in middle stand hidden layers which have no direct contact with the environment.

The developed ANN consists of multilayer feedforward: input, hidden and output layers as illustrated in Fig. 2.

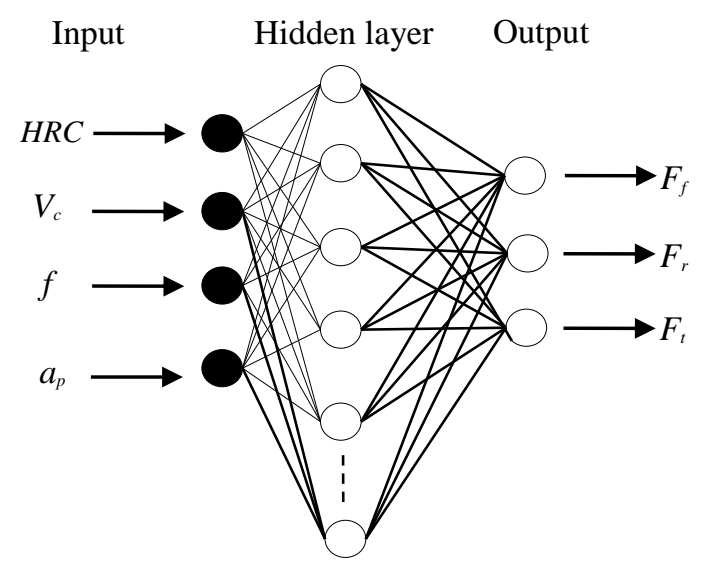

Fig. 2 Architecture of the developed ANN 
Let us recall that the machining parameters such as cutting speed $V_{c}$, feed $f$, dept-of-cut $a_{p}$ and workpiece hardness $H R C$ are taken as input vector of the ANN while machining force components such as feed-force $F_{f}$, radial-force $F_{r}$ and tangential-force $F_{t}$ are the outputs.

Fig. 3 shows the cutting parameters and the cutting force components in turning process.

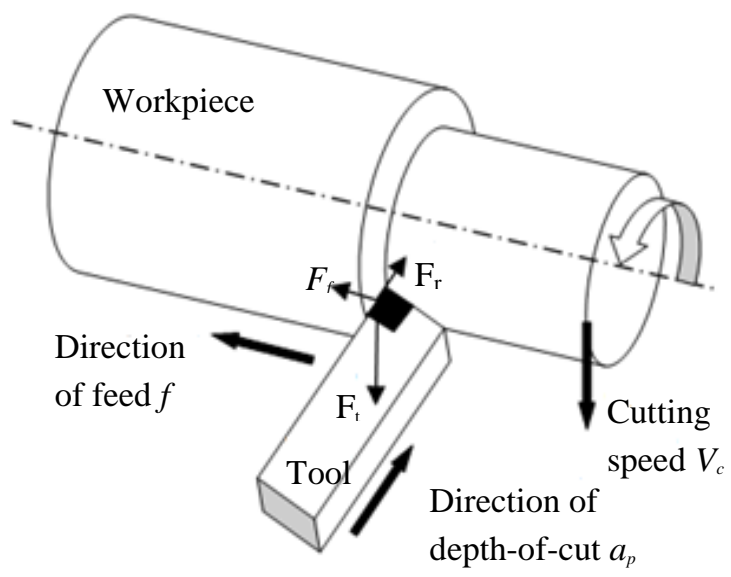

Fig. 3 Machining force components in turning process

The selection of transfer functions in the hidden and output layers, number of hidden layers and neurons in a hidden layer are very important to obtain the best prediction results. In this study, the optimal network architecture is determined after several simulations by Matlab Neural Network Toolbox. The methodology used to obtain the optimal network architecture is summarized below in section 2.2.

The basic goal in training is to minimize the overall error of the network between target or experimental data and network output, and then the best network structure was determined. The training is stopped when the validation error reaches a minimum value. For the developed ANN, Back-Propagation (BP) by Bayesian Regularization (BR) in combination with Levenberg-Marquardt (LM) algorithm is employed for training. Since, it has proved that BP algorithm is an excellent universal approximator of non-linear functions.

The performance evaluation of the optimum network architecture is determined by overall calculated statistical error values as SSE (Sum Squared Errors) and SSW (Sum Squared Weights) under Matlab Neural Network Toolbox for the ANN between target data and network output during training and testing phases. Additionally, to find the optimal network architecture, linear regression coefficient $R$ Eq. (2) [14] and Mean Absolute Percentage Error MAPE Eq. (3) [10] between ANN prediction and experimental values are used to evaluate the statistical performance of the network for training and testing phases.

$$
\begin{aligned}
& R=\sqrt{\frac{\sum_{k=1}^{Q}(s(k)-\bar{c})^{2}}{\sum_{k=1}^{Q}(c(k)-s(k))^{2}+\sum_{k=1}^{Q}(s(k)-\bar{c})^{2}} .} \\
& \operatorname{MAPE}(\%)=\frac{|c(k)-s(k)|}{c(k)} .
\end{aligned}
$$

A linear regression model that contains more than one predictor variable is called a Multiple Linear Regression model. MLR attempts to model the relationship between two or more explanatory variables and a response variable by fitting a linear equation to observed data.

In this context, we propose nonlinear models to predict the machining force components; the mathematical formulation is given by the following equations:

$$
\begin{aligned}
& F_{f}=K_{1} \cdot H R C^{\alpha_{1}} \cdot V_{c}^{\beta_{1}} \cdot f^{\gamma_{1}} \cdot a_{p}^{\delta_{1}} \cdot, \\
& F_{r}=K_{2} \cdot H R C^{\alpha_{2}} \cdot V_{c}^{\beta_{2}} \cdot f^{\gamma_{2}} \cdot a_{p}^{\delta_{2}} . \\
& F_{t}=K_{3} \cdot H R C^{\alpha_{3}} \cdot V_{c}^{\beta_{3}} \cdot f^{\gamma_{3}} \cdot a_{p}^{\delta_{3}} .
\end{aligned}
$$

These equations are put in linear form by using the natural logarithm as follows:

$$
\begin{aligned}
& \ln \left(F_{f}\right)=\ln K_{1}+\alpha_{1} \ln H R C+\beta_{1} \ln V_{c}+\gamma_{1} \ln f+\delta_{1} \ln a_{p} . \\
& \ln \left(F_{r}\right)=\ln K_{2}+\alpha_{2} \ln H R C+\beta_{2} \ln V_{c}+\gamma_{2} \ln f+\delta_{2} \ln a_{p} . \\
& \ln \left(F_{t}\right)=\ln K_{3}+\alpha_{3} \ln H R C+\beta_{3} \ln V_{c}+\gamma_{3} \ln f+\delta_{3} \ln a_{p} .
\end{aligned}
$$

The variables to be explained by the MLR models are: $\ln \left(F_{f}\right), \ln \left(F_{r}\right)$ and $\ln \left(F_{t}\right)$, and the independent variables are: $\ln (H R C), \ln \left(V_{c}\right), \ln (f)$ and $\ln \left(a_{p}\right)$.

\subsection{Experimental dataset for training and testing the de- veloped ANN}

The main objective of the experimental work was to investigate the influence of cutting parameters $\left(V_{c}, f\right.$ and $a_{p}$ ) and workpiece hardness $(H R C)$ on machining force in hard turning of AISI 52100 bearing steel using CBN cutting tool. The components of machining force were measured by a piezoelectric dynamometer Kistler type $9257 \mathrm{~B}$.

The AISI 52100 bearing steel with the following chemical composition was used as workpiece in turning: $1.05 \% \mathrm{C} ; 1.481 \% \mathrm{Cr} ; 0.033 \% \mathrm{Cu} ; 0.018 \% \mathrm{~S} ; 0.239 \% \mathrm{Si}$; $0.01 \% \mathrm{Mo} ; 0.365 \% \mathrm{Mn} ; 0.009 \% \mathrm{P}$. After heat treatment an average hardness from 45 to $55.25 \mathrm{HRC}$ was obtained. CBN inserts VBGW160408NC-2 (Sumitomo) were used to machining AISI 52100 bearing steel under CNC lathe type Ramo (RACN82).

The experimental dataset is divided into two databases as training and test bases. On a total of 35 examples, $70 \%$ will be intended for the training and $30 \%$ will be reserved for the test. The training of the developed ANN is performed on 25 pairs of input-target dataset as shown on Table 1.

The generalization capability is evaluated on 10 further pairs of input-target dataset (Table 2) that were not been used in training dataset.

Notice that before training and testing the network, the values which are set of input and target vectors are normalized in the range of -1 to 1 for efficient processing by the ANN. 
Table 1

Training dataset [10]

\begin{tabular}{|c|c|c|c|c|c|c|c|}
\hline \multirow{2}{*}{ Test $n^{o}$} & \multicolumn{4}{|c|}{ Machining parameters } & \multicolumn{3}{|c|}{ Experimental components of cutting force } \\
\hline & $H R C$ & $V_{c}, \mathrm{~m} / \mathrm{min}$ & $f, \mathrm{~mm} / \mathrm{rev}$ & $a_{p}, \mathrm{~mm}$ & $F_{f}, \mathrm{~N}$ & $F_{r}, \mathrm{~N}$ & $F_{t}, \mathrm{~N}$ \\
\hline 1 & 45 & 100 & 0.1 & 0.2 & 55.81 & 102.60 & 127.14 \\
\hline 2 & 45 & 150 & 0.05 & 0.2 & 20.23 & 50.52 & 50.04 \\
\hline 3 & 45 & 150 & 0.1 & 0.2 & 27.64 & 70.66 & 82.64 \\
\hline 4 & 45 & 150 & 0.1 & 0.3 & 60.05 & 117.77 & 135.27 \\
\hline 5 & 45 & 150 & 0.15 & 0.2 & 42.25 & 115.01 & 135.60 \\
\hline 6 & 45 & 200 & 0.1 & 0.2 & 32.82 & 78.86 & 90.70 \\
\hline 7 & 50 & 100 & 0.1 & 0.2 & 41.36 & 110.99 & 106.12 \\
\hline 8 & 50 & 150 & 0.05 & 0.2 & 34.89 & 102.99 & 68.77 \\
\hline 9 & 50 & 150 & 0.1 & 0.4 & 90.41 & 157.68 & 178.67 \\
\hline 10 & 50 & 150 & 0.2 & 0.2 & 58.09 & 193.25 & 168.47 \\
\hline 11 & 50 & 200 & 0.1 & 0.1 & 35.84 & 97.29 & 93.98 \\
\hline 12 & 51.5 & 50 & 0.1 & 0.2 & 44.31 & 102.87 & 116.84 \\
\hline 13 & 51.5 & 150 & 0.1 & 0.2 & 37.73 & 101.78 & 97.76 \\
\hline 14 & 51.5 & 250 & 0.1 & 0.2 & 36.80 & 96.79 & 94.55 \\
\hline 15 & 51.5 & 300 & 0.1 & 0.4 & 59.04 & 111.98 & 135.02 \\
\hline 16 & 54 & 100 & 0.1 & 0.2 & 34.01 & 85.25 & 96.05 \\
\hline 17 & 54 & 150 & 0.05 & 0.2 & 23.40 & 58.13 & 55.61 \\
\hline 18 & 54 & 150 & 0.1 & 0.3 & 57.34 & 114.92 & 131.04 \\
\hline 19 & 54 & 150 & 0.15 & 0.2 & 40.27 & 110.19 & 127.85 \\
\hline 20 & 54 & 150 & 0.2 & 0.2 & 45.01 & 140.02 & 159.01 \\
\hline 21 & 54 & 200 & 0.1 & 0.2 & 35.26 & 91.26 & 92.00 \\
\hline 22 & 55.25 & 50 & 0.1 & 0.2 & 51.46 & 140.99 & 120.74 \\
\hline 23 & 55.25 & 150 & 0.1 & 0.2 & 29.57 & 74.71 & 86.18 \\
\hline 24 & 55.25 & 200 & 0.1 & 0.2 & 17.90 & 57.63 & 61.39 \\
\hline 25 & 55.25 & 300 & 0.1 & 0.2 & 32.36 & 97.29 & 91.68 \\
\hline
\end{tabular}

Table 2

Testing dataset [10]

\begin{tabular}{|c|c|c|c|c|c|c|c|}
\hline \multirow{2}{*}{ Test $n^{\text {o }}$} & \multicolumn{4}{|c|}{ Machining parameters } & \multicolumn{3}{c|}{ Experimental components of cutting force } \\
\cline { 2 - 8 } & $H R C$ & $V_{c}, \mathrm{~m} / \mathrm{min}$ & $f, \mathrm{~mm} / \mathrm{rev}$ & $a_{p}, \mathrm{~mm}$ & $F_{f}, \mathrm{~N}$ & $F_{r}, \mathrm{~N}$ & $F_{t}, \mathrm{~N}$ \\
\hline 26 & 45 & 150 & 0.08 & 0.2 & 28.01 & 68.62 & 75.25 \\
\hline 27 & 45 & 150 & 0.12 & 0.1 & 16.04 & 60.37 & 62.84 \\
\hline 28 & 50 & 150 & 0.1 & 0.3 & 65.80 & 154.11 & 142.81 \\
\hline 29 & 50 & 150 & 0.15 & 0.2 & 46.37 & 139.42 & 136.84 \\
\hline 30 & 51.5 & 50 & 0.1 & 0.4 & 57.83 & 115.47 & 140.18 \\
\hline 31 & 51.5 & 300 & 0.1 & 0.2 & 32.29 & 89.28 & 92.64 \\
\hline 32 & 54 & 150 & 0.1 & 0.2 & 32.30 & 90.61 & 93.54 \\
\hline 33 & 54 & 150 & 0.1 & 0.4 & 82.76 & 142.35 & 172.37 \\
\hline 34 & 55.25 & 100 & 0.1 & 0.2 & 33.38 & 80.99 & 95.66 \\
\hline 35 & 55.25 & 250 & 0.1 & 0.2 & 33.48 & 77.61 & 92.81 \\
\hline
\end{tabular}

\subsection{Optimal network architecture and simulation results}

The best results for training are obtained when the transfer function of the output layer is linear and it is hyperbolic tangent sigmoid for the hidden layer.

In the same context, Table 3 shows a comparative study between two configurations during training. For the first configuration (S/L), the transfer function of the output layer is linear and it is hyperbolic tangent sigmoid for the hidden layer. On the other hand, for the second configuration $(\mathrm{S} / \mathrm{S})$, the transfer functions of the output and hidden layers are hyperbolic tangent sigmoid.
The representative criteria, adopted for $(\mathrm{S} / \mathrm{L})$ and (S/S) configurations, is the linear regression coefficient $R$.

From Table 3, we can see that the $(\mathrm{S} / \mathrm{L})$ configuration gives the best coefficient $\mathrm{R}$ during training phase.

In order to define the optimal architecture, a various number of neurons in the hidden layer have been tested from 1 to 12 with step of 1 . Four representative criteria are adopted for each structure and collected in Table 4; namely: SSE, SSW, $R$ for training and testing, and MAPE Testing. 
Comparison between $(\mathrm{S} / \mathrm{L})$ and $(\mathrm{S} / \mathrm{S})$ configurations

\begin{tabular}{|c|c|c|}
\hline ANN Structure & $R-$ Training (S/L) & $R-$ Training (S/S) \\
\hline $4-1-3$ & 0.878 & 0.562 \\
\hline $4-2-3$ & 0.921 & -0.131 \\
\hline $4-3-3$ & 0.962 & 0.351 \\
\hline $4-4-3$ & 0.982 & 0.216 \\
\hline $4-5-3$ & 0.985 & -0.131 \\
\hline $4-6-3$ & 0.997 & 0.647 \\
\hline $4-7-3$ & 0.999 & 0.703 \\
\hline $4-8-3$ & 0.999 & 0.620 \\
\hline $4-9-3$ & 0.999 & 0.113 \\
\hline $4-10-3$ & 0.999 & 0.818 \\
\hline $4-11-3$ & 1 & 0.485 \\
\hline $4-12-3$ & 1 & 0.518 \\
\hline
\end{tabular}

Criteria values for each structure

Table 4

\begin{tabular}{|c|c|c|c|c|c|}
\hline ANN Structure & SSE & SSW & $R$ - Training & $R$ - Testing & MAPE Testing (\%) \\
\hline $4-1-3$ & 15.771 & 0.121 & 0.199 & 0.207 & 35.76 \\
\hline $4-2-3$ & 2.465 & 33.158 & 0.921 & 0.841 & 18.32 \\
\hline $4-3-3$ & 2.214 & 38.213 & 0.930 & 0.828 & 18.26 \\
\hline $4-4-3$ & 0.705 & 102.809 & 0.978 & 0.866 & 19.31 \\
\hline $4-5-3$ & 2.063 & 40.340 & 0.935 & 0.826 & 18.71 \\
\hline $4-6-3$ & 2.035 & 41.149 & 0.936 & 0.823 & 18.92 \\
\hline $4-7-3$ & 0.082 & 192.444 & 0.997 & 0.910 & 14.28 \\
\hline $4-8-3$ & 0.043 & 212.589 & 0.998 & 0.922 & 14.24 \\
\hline $4-9-3$ & 0.007 & 246.724 & 0.999 & 0.845 & 18.56 \\
\hline $4-10-3$ & 2.056 & 40.395 & 0.935 & 0.825 & 18.72 \\
\hline $4-11-3$ & 0.004 & 223.386 & 0.999 & 0.934 & 13.00 \\
\hline $4-12-3$ & 2.039 & 40.946 & 0.935 & 0.824 & 18.85 \\
\hline
\end{tabular}

From Table 4, we can see that the structure consisting of 11 neurons in hidden layer is chosen as the optimum ANN structure. Notice that the training algorithm converges if the SSE and the SSW are relatively constant over several iterations for each structure; the error of the network is minimized and then the best network architecture is selected.

The evolution of SSE value as a function of SSW value is plotted on Fig. 4.

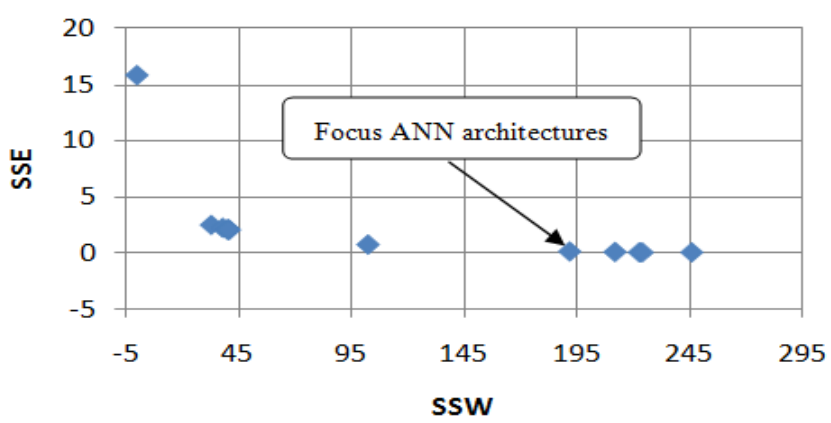

Fig. 4 Decrease of SSE during training of different ANN structures

Notice that the best ANN structure is chosen in the convergence area where SSE is slightly close to 0 and SSW is between 192 and 247. For this area, it can see from Table 4 that the number of neurons in hidden layer must reach 7 .

Let us recall, that the developed ANN consists of
4 inputs and of an output layer having 3 neurons. Also, the results given in Tables 3 and 4 are obtained for a single hidden layer. To show the influence of the number of hidden layers, two structures were adopted; in the first one, the single hidden layer have 11 neurons, and the second structure makes up of two hidden layers having respectively 6 and 11 neurons. Fig. 5 illustrates a graphical comparison between the two structures for the prediction of tangential-force during training.

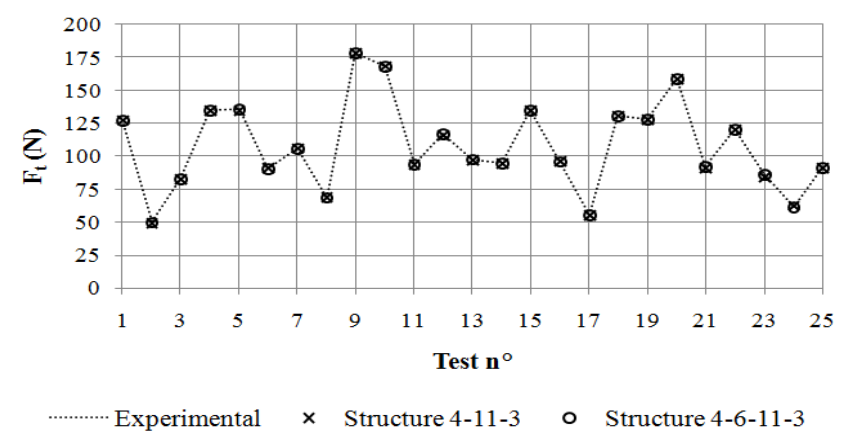

Fig. 5 Comparison between 4-11-3 and 4-6-11-3 structures

According to the last figure, it is preferable to choose only one hidden layer because the two structures give the same results.

Under Matlab Neural Network Toolbox, the developed ANN can be shown as follows in Fig. 6. 


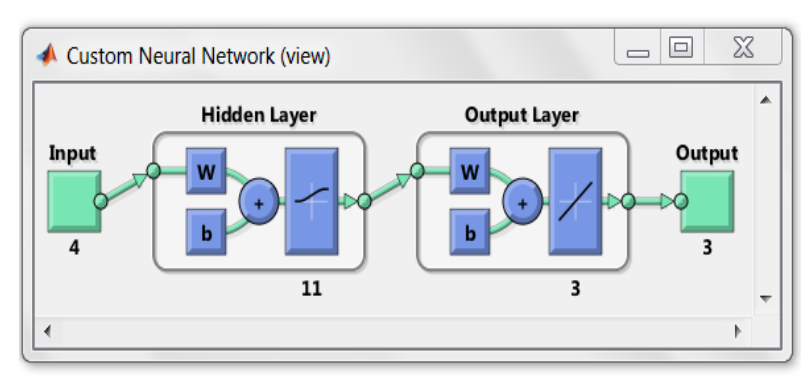

Fig. 6 Developed ANN structure under Matlab
The optimal architecture of the developed ANN consists of multilayer feed-forward with 4-11-3 structure. Back-Propagation (BP) by Bayesian Regularization (BR) in combination with Levenberg-Marquardt (LM) algorithm is employed for training.

Table 5 gives a numerical comparison between experimental and predicted machining force components during training phase.

Comparison between experimental and predicted values of machining force components during training

Table 5

\begin{tabular}{|c|c|c|c|c|c|c|c|c|c|}
\hline \multirow{2}{*}{ Test $n^{\circ}$} & \multicolumn{3}{|c|}{ Experimental components } & \multicolumn{3}{|c|}{ Predicted components } & \multicolumn{3}{|c|}{ MAPE (\%) } \\
\hline & $F_{f}$ & $F_{r}$ & $F_{t}$ & $F_{f}$ & $F_{r}$ & $F_{t}$ & $\left(F_{f}\right)$ & $\left(F_{r}\right)$ & $\left(F_{t}\right)$ \\
\hline 1 & 55.81 & 102.60 & 127.14 & 55.31 & 103.08 & 127.73 & 0.89 & 0.47 & 0.46 \\
\hline 2 & 20.23 & 50.52 & 50.04 & 20.52 & 50.79 & 49.38 & 1.47 & 0.53 & 1.32 \\
\hline 3 & 27.64 & 70.66 & 82.64 & 27.85 & 69.89 & 82.99 & 0.77 & 1.09 & 0.41 \\
\hline 4 & 60.05 & 117.77 & 135.27 & 60.21 & 117.63 & 135.00 & 0.27 & 0.12 & 0.20 \\
\hline 5 & 42.25 & 115.01 & 135.60 & 42.57 & 114.99 & 134.92 & 0.75 & 0.02 & 0.50 \\
\hline 6 & 32.82 & 78.86 & 90.70 & 32.37 & 79.09 & 91.24 & 1.37 & 0.29 & 0.60 \\
\hline 7 & 41.36 & 110.99 & 106.12 & 41.37 & 110.40 & 106.29 & 0.02 & 0.54 & 0.16 \\
\hline 8 & 34.89 & 102.99 & 68.77 & 34.65 & 102.81 & 69.12 & 0.69 & 0.17 & 0.51 \\
\hline 9 & 90.41 & 157.68 & 178.67 & 90.32 & 157.80 & 178.72 & 0.10 & 0.08 & 0.03 \\
\hline 10 & 58.09 & 193.25 & 168.47 & 57.96 & 193.26 & 168.76 & 0.23 & 0.00 & 0.17 \\
\hline 11 & 35.84 & 97.29 & 93.98 & 35.87 & 97.23 & 93.86 & 0.09 & 0.06 & 0.13 \\
\hline 12 & 44.31 & 102.87 & 116.84 & 44.53 & 102.78 & 116.52 & 0.49 & 0.09 & 0.28 \\
\hline 13 & 37.73 & 101.78 & 97.76 & 38.01 & 103.04 & 97.28 & 0.74 & 1.24 & 0.49 \\
\hline 14 & 36.80 & 96.79 & 94.55 & 37.00 & 96.76 & 94.48 & 0.55 & 0.03 & 0.08 \\
\hline 15 & 59.04 & 111.98 & 135.02 & 59.05 & 111.97 & 135.02 & 0.00 & 0.00 & 0.00 \\
\hline 16 & 34.01 & 85.25 & 96.05 & 33.50 & 85.79 & 96.72 & 1.52 & 0.64 & 0.70 \\
\hline 17 & 23.40 & 58.13 & 55.61 & 23.32 & 58.25 & 55.71 & 0.36 & 0.20 & 0.18 \\
\hline 18 & 57.34 & 114.92 & 131.04 & 57.38 & 114.77 & 131.08 & 0.07 & 0.13 & 0.04 \\
\hline 19 & 40.27 & 110.19 & 127.85 & 39.95 & 110.27 & 128.33 & 0.78 & 0.07 & 0.38 \\
\hline \multirow{2}{*}{ Test $n^{\circ}$} & \multicolumn{3}{|c|}{ Experimental components } & \multicolumn{3}{|c|}{ Predicted components } & \multicolumn{3}{|c|}{ MAPE (\%) } \\
\hline & $F_{f}$ & $F_{r}$ & $F_{t}$ & $F_{f}$ & $F_{r}$ & $F_{t}$ & $\left(F_{f}\right)$ & $\left(F_{r}\right)$ & $\left(F_{t}\right)$ \\
\hline 20 & 45.01 & 140.02 & 159.01 & 45.15 & 140.01 & 158.72 & 0.31 & 0.00 & 0.18 \\
\hline 21 & 35.26 & 91.26 & 92.00 & 35.22 & 89.79 & 91.41 & 0.12 & 1.62 & 0.65 \\
\hline 22 & 51.46 & 140.99 & 120.74 & 51.59 & 140.74 & 120.65 & 0.26 & 0.18 & 0.07 \\
\hline 23 & 29.57 & 74.71 & 86.18 & 30.09 & 74.44 & 84.88 & 1.75 & 0.36 & 1.50 \\
\hline 24 & 17.90 & 57.63 & 61.39 & 17.72 & 58.34 & 62.80 & 1.02 & 1.24 & 2.30 \\
\hline 25 & 32.36 & 97.29 & 91.68 & 32.34 & 97.48 & 91.52 & 0.04 & 0.20 & 0.17 \\
\hline \multicolumn{7}{|c|}{ Average MAPE (\%) } & 0.59 & 0.37 & 0.46 \\
\hline
\end{tabular}

The developed ANN gives precise results for the prediction of machining force components during training phase; average MAPEs of $0.59 \%, 0.37 \%$ and $0.46 \%$ are respectively noted on $F_{f}, F_{r}$ and $F_{t}$.
Table 6 illustrates cutting conditions used to test the developed ANN as well as the corresponding experimental and predicted machining force components.

Comparison between experimental and predicted values during test

Table 6

\begin{tabular}{|c|c|c|c|c|c|c|c|c|c|}
\hline Test $n^{\circ}$ & \multicolumn{3}{|c|}{ Experimental components } & \multicolumn{3}{c|}{ Predicted components } & \multicolumn{4}{c|}{ MAPE $(\%)$} \\
\hline & $F_{f}$ & $F_{r}$ & $F_{t}$ & $F_{f}$ & $F_{r}$ & $F_{t}$ & $\left(F_{f}\right)$ & $\left(F_{r}\right)$ & $\left(F_{t}\right)$ \\
\hline 26 & 55.81 & 102.60 & 127.14 & 55.31 & 103.08 & 127.73 & 0.89 & 0.47 & 0.46 \\
\hline 27 & 20.23 & 50.52 & 50.04 & 20.52 & 50.79 & 49.38 & 1.47 & 0.53 & 1.32 \\
\hline 28 & 27.64 & 70.66 & 82.64 & 27.85 & 69.89 & 82.99 & 0.77 & 1.09 & 0.41 \\
\hline 29 & 60.05 & 117.77 & 135.27 & 60.21 & 117.63 & 135.00 & 0.27 & 0.12 & 0.20 \\
\hline
\end{tabular}


Comparison between experimental and predicted values during test

\begin{tabular}{|c|c|c|c|c|c|c|c|c|c|}
\hline \multirow{2}{*}{$\begin{array}{c}\text { Test } n \\
30\end{array}$} & \multicolumn{3}{|c|}{ Experimental components } & \multicolumn{3}{|c|}{ Predicted components } & \multicolumn{3}{|c|}{ MAPE (\%) } \\
\hline & 42.25 & 115.01 & 135.60 & 42.57 & 114.99 & 134.92 & 0.75 & 0.02 & 0.50 \\
\hline 31 & 32.82 & 78.86 & 90.70 & 32.37 & 79.09 & 91.24 & 1.37 & 0.29 & 0.60 \\
\hline 32 & 41.36 & 110.99 & 106.12 & 41.37 & 110.40 & 106.29 & 0.02 & 0.54 & 0.16 \\
\hline 33 & 34.89 & 102.99 & 68.77 & 34.65 & 102.81 & 69.12 & 0.69 & 0.17 & 0.51 \\
\hline 34 & 90.41 & 157.68 & 178.67 & 90.32 & 157.80 & 178.72 & 0.10 & 0.08 & 0.03 \\
\hline 35 & 58.09 & 193.25 & 168.47 & 57.96 & 193.26 & 168.76 & 0.23 & 0.00 & 0.17 \\
\hline \multicolumn{7}{|c|}{ Average MAPE (\%) } & 14.55 & 12.73 & 11.73 \\
\hline
\end{tabular}

The average MAPEs of $14.55 \%, 12.73 \%$ and $11.73 \%$ are respectively noted on $F_{f}, F_{r}$ and $F_{t}$ during the test phase.

Fig. 7 illustrates a graphical comparison between experimental and predicted machining force components for test phase.

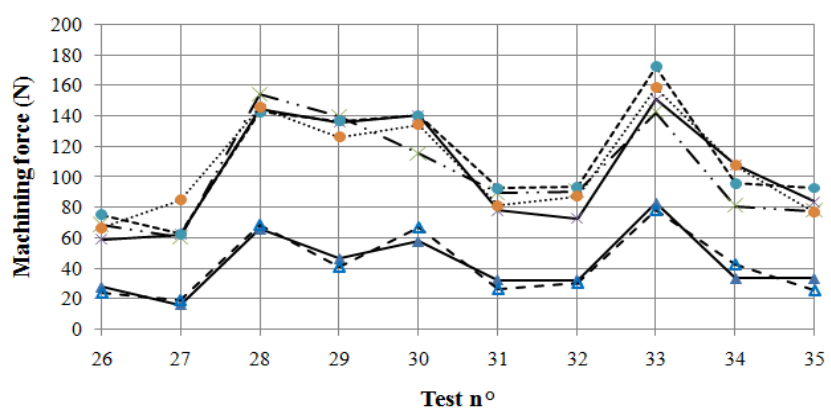

$$
\begin{aligned}
& \text {-Ff - Experimental } \\
& - \text { Fr - Experimental } \\
& -- \text { Ft - Experimental }
\end{aligned}
$$

Fig. 7 Comparison between experimental and predicted machining force components during test phase

Tables 7 and 8 gives respectively the performances of the developed ANN and the analysis of variance as follows.

Table 7

Performances of the developed ANN

\begin{tabular}{|c|c|c|c|c|c|}
\hline Structure & SSE & SSW & $\begin{array}{c}R-\text { Train- } \\
\text { ing }\end{array}$ & $\begin{array}{c}R- \\
\text { Testing }\end{array}$ & $\begin{array}{c}R- \\
\text { ANN }\end{array}$ \\
\hline $4-11-3$ & 0.004 & 223.386 & 0.999 & 0.934 & 0.978 \\
\hline \multicolumn{6}{|c|}{ Linear regression coefficients } \\
\hline$R^{2}\left(F_{f}\right)=96.7 \%$ & $R^{2}\left(F_{r}\right)=94.5 \%$ & $R^{2}\left(F_{t}\right)=96.1 \%$ \\
\hline \multicolumn{6}{c|}{ Average MAPEs for the ANN } \\
\hline $4.58 \%$ for $\left(F_{f}\right)$ & $3.90 \%$ for $\left(F_{r}\right)$ & $3.68 \%$ for $\left(F_{t}\right)$ \\
\hline
\end{tabular}

Table 8

Analysis of variance for the ANN approach

\begin{tabular}{|c|l|l|l|l|c|}
\hline \multicolumn{2}{|c|}{ Source } & Sum of Squares & Df & Mean Square & $\begin{array}{c}\text { F- } \\
\text { Ratio }\end{array}$ \\
\hline \multirow{2}{*}{$F_{f}$} & Model & 10001.80 & 4 & 2500.45 & \multirow{2}{*}{220.34} \\
\cline { 2 - 6 } & Residual & 340.45 & 30 & 11.35 & \\
\hline \multirow{2}{*}{$F_{r}$} & Model & 36439.01 & 4 & 9109.75 & \multirow{2}{*}{128.99} \\
\cline { 2 - 6 } & Residual & 2118.70 & 30 & 70.62 & \\
\hline \multirow{2}{*}{$F_{t}$} & Model & 36703.57 & 4 & 9175.89 & \multirow{2}{*}{184.83} \\
\cline { 2 - 5 } & Residual & 1489.37 & 30 & 49.65 & \\
\hline
\end{tabular}

\subsection{Multiple Linear Regression modeling}

The prediction models of the machining force components with MLR are given by the following equations:

- the component $F_{f}$ with $R^{2}=92.5 \%$ is expressed by:

$$
\begin{aligned}
& \ln \left(F_{f}\right)=7.31419+0.17844 \cdot \ln H R C \\
& -0.21268 \cdot \ln V_{c}+0.60292 \cdot \ln f+1.25507 \cdot \ln a_{p} .
\end{aligned}
$$

- the component $F_{r}$ with $R^{2}=82.2 \%$ is voiced by:

$$
\begin{aligned}
& \ln \left(F_{r}\right)=7.11439+0.29941 \cdot \ln H R C \\
& -0.17022 \cdot \ln V_{c}+0.78193 \cdot \ln f+0.70274 \cdot \ln a_{p} .
\end{aligned}
$$

- the component $F_{t}$ with $R^{2}=96.6 \%$ is given by:

$$
\begin{aligned}
& \ln \left(F_{t}\right)=8.02677+0.12830 \cdot \ln H R C \\
& -0.15214 \cdot \ln V_{c}+0.82226 \cdot \ln f+0.81963 \cdot \ln a_{p} .
\end{aligned}
$$

From these equations, we can see that the machining force components increase with the augmentation of workpiece hardness, feed and depth-of-cut; but, it decreases with the augmentation of cutting speed.

Table 9 gives the analysis of variance for Multiple Linear Regression modeling. Notice that the tests $n^{\circ} 1,8$, 11,24 and 30 are eliminated to ovoid studentized residuals greater than 3 in absolute value and to give best performances (high linear regression coefficient $R$ ).

Table 9

Analysis of variance for MLR modeling

\begin{tabular}{|c|c|c|c|c|c|}
\hline \multicolumn{2}{|c|}{ Source } & $\begin{array}{c}\text { Sum of } \\
\text { Squares }\end{array}$ & $D f$ & $\begin{array}{c}\text { Mean } \\
\text { Square }\end{array}$ & \multirow{2}{*}{$F$-Ratio } \\
\hline \multirow{2}{*}{$L n F_{f}$} & Model & 4.03937 & 4 & 1.00984 & \multirow{2}{*}{77.05} \\
\cline { 2 - 6 } & Residual & 0.327677 & 25 & 0.013107 & \\
\hline \multirow{2}{*}{$L n F_{r}$} & Model & 2.44779 & 4 & 0.61195 & \multirow{2}{*}{28.82} \\
\cline { 2 - 6 } & Residual & 0.530796 & 25 & 0.021232 & \\
\hline \multirow{2}{*}{$L n F_{t}$} & Model & 2.85884 & 4 & 0.71471 & \multirow{2}{*}{179.48} \\
\cline { 2 - 5 } & Residual & 0.099553 & 25 & 0.003982 & \\
\hline
\end{tabular}

Table 10 gives the analysis of variance by considering all tests (35 examples) as follows.

Notice that the squared linear regression coefficients of $75.9 \%, 67.6 \%$ and $84.7 \%$ are respectively noted 
on $\left(F_{f}\right),\left(F_{r}\right)$ and $\left(F_{t}\right)$ by considering all tests (35 examples).

Table 11 gives a numerical comparison between experimental and predicted MLR values of the machining force components.

It can be seen that the MLR modeling gives the average MAPEs of $16.15 \%, 15.71 \%$ and $9.37 \%$ which are respectively noted on $F_{f}, F_{r}$ and $F_{t}$.
Table 10

Analysis of variance for MLR modeling (all tests)

\begin{tabular}{|c|c|c|c|c|c|}
\hline \multicolumn{2}{|c|}{ Source } & $\begin{array}{c}\text { Sum of } \\
\text { Squares }\end{array}$ & Df & Mean Square & \multirow{2}{*}{ F-Ratio } \\
\hline \multirow{2}{*}{$F_{f}$} & Model & 12851.95 & 4 & 3212.99 & \multirow{2}{*}{23.66} \\
\cline { 2 - 6 } & Residual & 4073.71 & 30 & 135.79 & \multirow{2}{*}{15.64} \\
\hline \multirow{2}{*}{$F_{r}$} & Model & 34696.88 & 4 & 8674.22 & \multirow{2}{*}{41.63} \\
\cline { 2 - 6 } & Residual & 16639.82 & 30 & 554.66 & \\
\hline \multirow{2}{*}{$F_{t}$} & Model & 46959.94 & 4 & 11739.98 & \multirow{2}{*}{4} \\
\cline { 2 - 5 } & Residual & 8460.69 & 30 & 282.02 & \\
\hline
\end{tabular}

Table 11

Comparison between experimental and predicted MLR values of the machining force components

\begin{tabular}{|c|c|c|c|c|c|c|c|c|c|}
\hline \multirow{2}{*}{ Test $n^{\circ}$} & \multicolumn{3}{|c|}{ Experimental components } & \multicolumn{3}{|c|}{ Predicted components } & \multicolumn{3}{|c|}{ MAPE (\%) } \\
\hline & $F_{f}$ & $F_{r}$ & $F_{t}$ & $F_{f}$ & $F_{r}$ & $F_{t}$ & $\left(F_{f}\right)$ & $\left(F_{r}\right)$ & $\left(F_{t}\right)$ \\
\hline 1 & 55.81 & 102.60 & 127.14 & 36.81 & 93.58 & 99.69 & 34.04 & 8.80 & 21.59 \\
\hline 2 & 20.23 & 50.52 & 50.04 & 22.23 & 50.79 & 53.01 & 9.91 & 0.54 & 5.93 \\
\hline 3 & 27.64 & 70.66 & 82.64 & 33.77 & 87.34 & 93.73 & 22.18 & 23.60 & 13.42 \\
\hline 4 & 60.05 & 117.77 & 135.27 & 56.17 & 116.13 & 130.68 & 6.46 & 1.39 & 3.39 \\
\hline 5 & 42.25 & 115.01 & 135.60 & 43.12 & 119.92 & 130.82 & 2.06 & 4.27 & 3.53 \\
\hline 6 & 32.82 & 78.86 & 90.70 & 31.77 & 83.16 & 89.72 & 3.21 & 5.46 & 1.08 \\
\hline 7 & 41.36 & 110.99 & 106.12 & 37.51 & 96.58 & 101.05 & 9.31 & 12.99 & 4.78 \\
\hline 8 & 34.89 & 102.99 & 68.77 & 22.66 & 52.42 & 53.73 & 35.06 & 49.10 & 21.87 \\
\hline 9 & 90.41 & 157.68 & 178.67 & 82.13 & 146.70 & 167.68 & 9.16 & 6.96 & 6.15 \\
\hline 10 & 58.09 & 193.25 & 168.47 & 52.26 & 154.98 & 167.99 & 10.03 & 19.80 & 0.29 \\
\hline 11 & 35.84 & 97.29 & 93.98 & 13.56 & 52.73 & 51.52 & 62.16 & 45.80 & 45.18 \\
\hline 12 & 44.31 & 102.87 & 116.84 & 43.70 & 109.64 & 112.72 & 1.38 & 6.58 & 3.53 \\
\hline \multirow{2}{*}{ Test $n^{\circ}$} & \multicolumn{3}{|c|}{ Experimental components } & \multicolumn{3}{|c|}{ Predicted components } & \multicolumn{3}{|c|}{ MAPE (\%) } \\
\hline & $F_{f}$ & $F_{r}$ & $F_{t}$ & $F_{f}$ & $F_{r}$ & $F_{t}$ & $\left(F_{f}\right)$ & $\left(F_{r}\right)$ & $\left(F_{t}\right)$ \\
\hline 13 & 37.73 & 101.78 & 97.76 & 34.59 & 90.94 & 95.37 & 8.32 & 10.65 & 2.45 \\
\hline 14 & 36.80 & 96.79 & 94.55 & 31.03 & 83.36 & 88.24 & 15.68 & 13.87 & 6.68 \\
\hline 15 & 59.04 & 111.98 & 135.02 & 71.25 & 131.53 & 151.47 & 20.68 & 17.46 & 12.18 \\
\hline 16 & 34.01 & 85.25 & 96.05 & 38.03 & 98.83 & 102.05 & 11.81 & 15.93 & 6.25 \\
\hline 17 & 23.40 & 58.13 & 55.61 & 22.97 & 53.64 & 54.26 & 1.84 & 7.72 & 2.42 \\
\hline 18 & 57.34 & 114.92 & 131.04 & 58.03 & 122.64 & 133.77 & 1.21 & 6.72 & 2.09 \\
\hline 19 & 40.27 & 110.19 & 127.85 & 44.55 & 126.65 & 133.92 & 10.62 & 14.93 & 4.74 \\
\hline 20 & 45.01 & 140.02 & 159.01 & 52.98 & 158.59 & 169.65 & 17.72 & 13.26 & 6.69 \\
\hline 21 & 35.26 & 91.26 & 92.00 & 32.82 & 87.83 & 91.84 & 6.93 & 3.76 & 0.17 \\
\hline 22 & 51.46 & 140.99 & 120.74 & 44.25 & 111.97 & 113.74 & 14.01 & 20.59 & 5.80 \\
\hline 23 & 29.57 & 74.71 & 86.18 & 35.03 & 92.87 & 96.23 & 18.46 & 24.31 & 11.66 \\
\hline 24 & 17.90 & 57.63 & 61.39 & 32.95 & 88.43 & 92.11 & 84.08 & 53.45 & 50.04 \\
\hline 25 & 32.36 & 97.29 & 91.68 & 30.23 & 82.53 & 86.60 & 6.59 & 15.17 & 5.54 \\
\hline 26 & 28.01 & 68.62 & 75.25 & 29.52 & 73.35 & 78.02 & 5.39 & 6.90 & 3.68 \\
\hline 27 & 16.04 & 60.37 & 62.84 & 15.79 & 61.88 & 61.70 & 1.54 & 2.50 & 1.82 \\
\hline 28 & 65.80 & 154.11 & 142.81 & 57.24 & 119.85 & 132.46 & 13.01 & 22.23 & 7.25 \\
\hline 29 & 46.37 & 139.42 & 136.84 & 43.94 & 123.76 & 132.60 & 5.24 & 11.23 & 3.10 \\
\hline 30 & 57.83 & 115.47 & 140.18 & 104.30 & 178.44 & 198.94 & 80.35 & 54.53 & 41.92 \\
\hline 31 & 32.29 & 89.28 & 92.64 & 29.85 & 80.82 & 85.82 & 7.55 & 9.48 & 7.36 \\
\hline 32 & 32.30 & 90.61 & 93.54 & 34.89 & 92.24 & 95.95 & 8.01 & 1.79 & 2.57 \\
\hline 33 & 82.76 & 142.35 & 172.37 & 83.27 & 150.12 & 169.34 & 0.61 & 5.46 & 1.76 \\
\hline 34 & 33.38 & 80.99 & 95.66 & 38.18 & 99.51 & 102.35 & 14.39 & 22.86 & 7.00 \\
\hline 35 & 33.48 & 77.61 & 92.81 & 31.42 & 85.14 & 89.04 & 6.14 & 9.70 & 4.07 \\
\hline \multicolumn{7}{|c|}{ Average MAPE (\%) } & 16.15 & 15.71 & 9.37 \\
\hline
\end{tabular}

\section{Comparison between ANN and MLR predictions}

For comparison between the values of the machining force components predicted by ANN and MLR modeling, the Root Mean Square Error (RMSE) [7] was used:

$$
R M S E=\sqrt{\frac{\sum_{k=1}^{O}(c(k)-s(k))^{2}}{Q}} .
$$

The Table 12 gives the RMSEs obtained by ANN and MLR modeling.

The results revealed that the ANN approach resulted into minimum RMSEs of the predicted machining force components compared to those obtained by MLR modeling. Also, the ANN approach gives minimum MAPEs, minimum mean square of residual sources and high squared linear regression coefficients. Notice, that the F-Ratios for ANN approach are greater than obtained by 
MLR modeling; for this purpose, the ANN regression is globally very significant.

Table 12

Comparison between RMSEs obtained by ANN and MLR modeling

\begin{tabular}{|c|c|c|c|c|c|c|}
\hline \multirow{2}{*}{$\begin{array}{l}\text { Test } \\
\text { no. }\end{array}$} & \multicolumn{3}{|c|}{ Predicted values by ANN } & \multicolumn{3}{|c|}{ Predicted values by MLR } \\
\hline & $F_{f}$ & $F_{r}$ & $F_{t}$ & $F_{f}$ & $F_{r}$ & $F_{t}$ \\
\hline 1 & 55.31 & 103.08 & 127.73 & 36.81 & 93.58 & 99.69 \\
\hline 2 & 20.52 & 50.79 & 49.38 & 22.23 & 50.79 & 53.01 \\
\hline \multirow{2}{*}{$\begin{array}{l}\text { Test } \\
\text { no. }\end{array}$} & \multicolumn{3}{|c|}{ Predicted values by ANN } & \multicolumn{3}{|c|}{ Predicted values by MLR } \\
\hline & $F_{f}$ & $F_{r}$ & $F_{t}$ & $F_{f}$ & $F_{r}$ & $F_{t}$ \\
\hline 3 & 27.85 & 69.89 & 82.99 & 33.77 & 87.34 & 93.73 \\
\hline 4 & 60.21 & 117.63 & 135.00 & 56.17 & 116.13 & 130.68 \\
\hline 5 & 42.57 & 114.99 & 134.92 & 43.12 & 119.92 & 130.82 \\
\hline 6 & 32.37 & 79.09 & 91.24 & 31.77 & 83.16 & 89.72 \\
\hline 7 & 41.37 & 110.40 & 106.29 & 37.51 & 96.58 & 101.05 \\
\hline 8 & 34.65 & 102.81 & 69.12 & 22.66 & 52.42 & 53.73 \\
\hline 9 & 90.32 & 157.80 & 178.72 & 82.13 & 146.70 & 167.68 \\
\hline 10 & 57.96 & 193.26 & 168.76 & 52.26 & 154.98 & 167.99 \\
\hline 11 & 35.87 & 97.23 & 93.86 & 13.56 & 52.73 & 51.52 \\
\hline 12 & 44.53 & 102.78 & 116.52 & 43.70 & 109.64 & 112.72 \\
\hline 13 & 38.01 & 103.04 & 97.28 & 34.59 & 90.94 & 95.37 \\
\hline 14 & 37.00 & 96.76 & 94.48 & 31.03 & 83.36 & 88.24 \\
\hline 15 & 59.05 & 111.97 & 135.02 & 71.25 & 131.53 & 151.47 \\
\hline 16 & 33.50 & 85.79 & 96.72 & 38.03 & 98.83 & 102.05 \\
\hline 17 & 23.32 & 58.25 & 55.71 & 22.97 & 53.64 & 54.26 \\
\hline 18 & 57.38 & 114.77 & 131.08 & 58.03 & 122.64 & 133.77 \\
\hline 19 & 39.95 & 110.27 & 128.33 & 44.55 & 126.65 & 133.92 \\
\hline 20 & 45.15 & 140.01 & 158.72 & 52.98 & 158.59 & 169.65 \\
\hline 21 & 35.22 & 89.79 & 91.41 & 32.82 & 87.83 & 91.84 \\
\hline 22 & 51.59 & 140.74 & 120.65 & 44.25 & 111.97 & 113.74 \\
\hline \multirow{2}{*}{$\begin{array}{l}\text { Test } \\
\text { no. }\end{array}$} & \multicolumn{3}{|c|}{ Predicted values by ANN } & \multicolumn{3}{|c|}{ Predicted values by MLR } \\
\hline & $F_{f}$ & $F_{r}$ & $F_{t}$ & $F_{f}$ & $F_{r}$ & $F_{t}$ \\
\hline 23 & 30.09 & 74.44 & 84.88 & 35.03 & 92.87 & 96.23 \\
\hline 24 & 17.72 & 58.34 & 62.80 & 32.95 & 88.43 & 92.11 \\
\hline 25 & 32.34 & 97.48 & 91.52 & 30.23 & 82.53 & 86.60 \\
\hline 26 & 24.05 & 59.12 & 66.76 & 29.52 & 73.35 & 78.02 \\
\hline 27 & 19.48 & 62.40 & 85.10 & 15.79 & 61.88 & 61.70 \\
\hline 28 & 68.51 & 144.38 & 145.46 & 57.24 & 119.85 & 132.46 \\
\hline 29 & 41.20 & 136.10 & 126.03 & 43.94 & 123.76 & 132.60 \\
\hline 30 & 66.69 & 140.55 & 134.11 & 104.30 & 178.44 & 198.94 \\
\hline 31 & 26.54 & 77.99 & 81.46 & 29.85 & 80.82 & 85.82 \\
\hline 32 & 30.40 & 72.76 & 87.30 & 34.89 & 92.24 & 95.95 \\
\hline 33 & 78.12 & 151.01 & 158.59 & 83.27 & 150.12 & 169.34 \\
\hline 34 & 42.42 & 107.90 & 107.46 & 38.18 & 99.51 & 102.35 \\
\hline 35 & 25.81 & 83.84 & 76.67 & 31.42 & 85.14 & 89.04 \\
\hline RMSE & 3.12 & 7.78 & 6.52 & 10.79 & 21.80 & 15.55 \\
\hline
\end{tabular}

\section{Conclusions}

The objective of this study is to develop an optimal ANN for prediction of machining force components in hard turning of AISI 52100 bearing steel with CBN cutting tool.

ANN training is performed on an experimental machining dataset of 25 examples and then the numerical model accuracy is evaluated on a further dataset of 10 values not used in training. Back-propagation training is performed by using Bayesian Regularization in combination with Levenberg-Marquardt algorithm. Hyperbolic tangent sigmoid transfer function is chosen in hidden layer and a linear one in output layer. Four criteria are used to evaluate the ANN efficiency: SSE, SSW, linear regression coefficient $\mathrm{R}$ and MAPE between ANN prediction and experimental values. A various number of neurons in hidden layer are tested; it is noticed that the optimal architecture is obtained when this number reaches 11 .

To show the effectiveness of the developed ANN, the results of machining force prediction are confronted with experimental data and to those obtained by MLR modeling. A good agreement is found between experimental and predicted values of the machining force components. The results revealed that the ANN approach resulted into minimum RMSEs of the predicted machining force components compared to those obtained by MLR modeling. Also, the ANN approach gives minimum MAPEs, minimum mean square of residual sources and high squared linear regression coefficients. Finally, the regression by ANN approach is globally very significant.

\section{References}

1. Luong, L. H. S.; Spedding, T. A. 1995. A neural network system for predicting machining behavior, Journal of Materials Processing Technology 52: 585-591. http://dx.doi.org/10.1016/0924-0136(94)01626-C.

2. Szecsi, T. 1999. Cutting force modeling using artificial neural networks, Journal of Materials Processing Technology (92-93): 344- 349. http://dx.doi.org/10.1016/S0924-0136(99)00183-1.

3. Ezugwu, E. O.; Fadare, D. A.; Bonney, J.; Da Silva, R. B.; Sales, W. F. 2005. Modeling the correlation between cutting and process parameters in high-speed machining of Inconel 718 alloy using an artificial neural network, International Journal of Machine Tools and Manufacture (45): 1375-1385.

http://dx.doi.org/10.1016/j.ijmachtools.2005.02.004.

4. Hao, W.; Zhu, X.; Li, X.; Turyagyenda, G. 2006. Prediction of cutting force for self-propelled rotary tool using artificial neural networks, Journal of Materials Processing Technology. (180): 23-29. http://dx.doi.org/10.1016/j.jmatprotec.2006.04.123

5. Sharma, V. S.; Dhiman, S.; Sehgal, R.; Sharma, S. K. 2008. Estimation of cutting forces and surface roughness for hard turning using neural networks, Journal of Intelligent Manufacturing 19 (4): 473-483. http://dx.doi.org/10.1007/s10845-008-0097-1.

6. Özel, T.; Esteves Correia, A.; Paulo Davim, J. 2009. Neural network process modeling for turning of steel parts using conventional and wiper inserts, International Journal of Materials and Product Technology 35 (Nos. 1/2.): 246-258.

http://dx.doi.org/10.1504/IJMPT.2009.025230.

7. Madić, M.; Radovavić, M. 2011. Methodology of developing optimal BP-ANN model for the prediction of cutting force in turning using Early Stopping method, Facta Universitatis, Series: Mechanical Engineering 9 (1): 21-32.

UDC 007.52, 621.941, 519.863.

8. Upadhyay, V.; Jain, P. K.; Mehta, N. K. 2011. Artificial Neural Network Modeling of Cutting Force in Turning of Ti-6Al-4V Alloy and Its Comparison with Response Surface Methodology, Proceedings of the International Conference on Soft Computing for Problem 
Solving (SocProS) December 20-22, Advances in Intelligent and Soft Computing (131): 761-768. http://dx.doi.org/10.1007/978-81-322-0491-6.

9. Cica, D.; Sredanovic, B; Lakic-Globocki, G.; Kramar D. 2013. Modeling of the cutting forces in turning process using various methods of cooling and lubricating: An artificial intelligence approach advances in mechanical engineering, Article ID 798597: 8 pages. http://dx.doi.org/10.1155/2013/798597.

10. Makhfi, S.; Velasco, R.; Habak, M.; Haddouche, K.; Vantomme, P. 2013. An Optimized ANN Approach for Cutting Forces Prediction in AISI 52100 Bearing Steel Hard Turning, Science and Technology 3(1): 2432. http://dx.doi.org/10.5923/j.scit.20130301.03.

11. Kara, F.; Aslantas, K.; Çiçek, A. 2015. ANN and multiple regression method-based modeling of cutting forces in orthogonal machining of AISI 316L stainless steel, Neural Computing and Applications 26 (1): 237 250. http://dx.doi.org/10.1007/S00521-014-1721-y.

12. Sharma, R. K.; Maurya, S.; Ranganath, M. S.; Vipin, 2016. Artificial Neural Network Modeling for Surface Roughness and Cutting Force during Conventional Turning Process, International Journal of Advanced Production and Industrial Engineering 1(3): 0105 .

IJAPIE-2016-07-301, VOL 1(3), 01-05.

13. Hagan, M. T.; Demuth, H. B.; Beale M. H.; De Jesús, O. 2014. Neural Network Design. 2nd Edition eBook.

ISBN 978-0-9717321-1-7

14. Montgomery D. C. 2005. Design and Analysis of Experiments. 6th Edition. ISBN 0-471-48735-X
S. Makhfi, K. Haddouche, A. Bourdim, M. Habak

\section{MODELING OF MACHINING FORCE IN HARD TURNING PROCESS}

S u m m a r y

In this work, we develop a modeling based on an Artificial Neural Network (ANN) and Multiple Linear Regression (MLR) to predict the machining force components generated during hard turning of a bearing steel with CBN cutting tool. The inputs of the ANN model were the cutting parameters (cutting speed, feed and depth-of-cut) and the workpiece hardness. The network training is performed by using experimental data. The optimal network architecture is determined after several simulations by Matlab Neural Network Toolbox. Back-propagation by Bayesian Regularization in combination with LevenbergMarquardt algorithm is employed for training. The ANN approach is suitable to estimate the machining force components such as feed-force, radial-force and tangentialforce; for this purpose, the results are compared to those obtained by experiment, and the maximum average MAPE value of $4.58 \%$ was obtained for the machining force prediction. Also, the ANN results were compared to those obtained by MLR model. It was shown that the ANN model produced more successful results.

Keywords: modeling, machining force, hard turning, bearing steel, CBN cutting tool, Artificial Neural Network, Multiple Linear Regression.

Received October 03, 2017

Accepted June 14, 2018 